\title{
INVESTIGATING THE IMPACT OF TELEWORKING MODEL ON WORK PERFORMANCE AND WORK CONDITIONS IN A ROMANIAN FAMILY BUSINESS
}

\author{
Lavinia CONSTANTINESCU ${ }^{a^{*}}$, Elena-Mirela NICHITA ${ }^{b}$, Mirela PAUUESCU $^{c}$ \\ ${ }^{a} 1$ Decembrie 1918 University, Alba-Iulia, România \\ ${ }^{b, c}$ Bucharest University of Economic Studies, România
}

\begin{abstract}
This research provides an analysis of the teleworking model during the times of pandemic COVID-19 and of the impact on employees' efficiency and shows how the business continuity was assured in a particular setup - a family business. Employing the single case study research methodology, this investigation intends to offer insights of the teleworking model in terms of interviewees' perceptions concerning the work conditions and work performance. The time framework analysed covers the period from March 2020 to June 2021. The data used was obtained through semi-structured interviews with key persons from relevant departments of the company, complemented with information extracted from internal reports. Several concepts related to the teleworking model are addressed: work performance, working conditions and individual perception of employees in respect to teleworking. Our analysis highlights employees' difficulties to adapt to the new work model caused by the absence of interactions with colleagues, which, in a family business, are assimilated to family members. The research acknowledges the need for digitalization of the company's processes and for maintaining the hybrid model of working in order to ensure the business continuousness. Our study contributes to the knowledge of how the teleworking model influences employees and family businesses, during the COVID-19 outbreak.
\end{abstract}

KEYWORDS: teleworking model, family business, work conditions, work performance, individual perception, COVID-19 Pandemic.

DOI: 10.24818/IMC/2021/04.05

\section{INTRODUCTION}

The unpredictable COVID-19 has brought in extreme and unexpected disruptions that have ravaged the world economy and will most likely produce the greatest rise in global unemployment in decades. As a result, businesses are implementing telework policies to ensure the continuity of business activity, but also to preserve the quality of life for employees and work efficiency. On the other hand, the COVID-19 Pandemic provides numerous opportunities for investigating the fundamental question of how the work will look in the future, both for employees and companies.

This research paper provides a snapshot study by examining contemporary issues namely telework in a family business and how it impacted the employees' welfare and business continuity during the Pandemic time (from March 2020 to June 2021).

Under current circumstances, managing a family business becomes a challenge in terms of trustworthiness to crucial stakeholders, particularly the employees. This is due to short-term

\footnotetext{
*Corresponding author. E-mail address: lavinia.constantinescu@temad.ro
} 
difficulties, complemented by the highly blurred future and disruption risks. Our investigation shows that teleworking imposed by COVID-19 crises contributes to employees' solitude by

limiting communications and interactions with colleagues, which are paramount in a family business. The resilient business model, specific to family businesses, supported the company investigated to meet financial forecasts for the analyzed period. The findings show that the current pandemics brought rapid digitalization in areas previously considered impossible to modernize.

The structure of the paper is as follows: the literature review will set the Pandemic context of research, and then the methodology will emphasize the considerations for applying the case study approach. The findings and result section will underline the challenges of telework and its impact on employees' and overall business performance and implications for future work policies applicable in business. Limitations and further considerations on telework in family businesses are mentioned at the end of the paper.

\section{LITERATURE REVIEW}

All relevant economic organizations analyze the impact of the Pandemic on economies. A year after the start of the Pandemic, it is clear that a lot of businesses were negatively affected, some of them even disappearing. However, all economic sectors all over the globe were impacted by the COVID-19 pandemic, but some trade and industry activities have been predominantly hard-hit, like non-essential services requiring a high degree of face-to-face interaction or production relying heavily on inputs from global supply chains. On other hand, some sectors underwent a slight decline in production: telecommunications, food, and healthcare (Fitch Ratings 2020; IFO Institute, 2020).

The primary concern relates to unemployment rates and workforce wellbeing. When there are sufficient digital capacities are in place, some jobs are easier to perform remotely, therefore, reduces unemployment risks (Fadinger et al. 2020). Considering sectoral exposure and company size, Doerr and Gambacorta (2020) identified that regions in Southern Europe (where the company studied is settles) and France have the highest shares of jobs under threat from the Pandemic, while risks are lower in Northern European regions.

Family businesses are at the heart of any economy. The pandemic crisis impacted this business in an irreversible way, irrespective of industry type and geographic location. Family firms tend to invest more in human capital such as employee involvement and cash profit sharing (Litz, 1995). In this paper, we use the definition of family business suggested by the European Commission (2009): "A firm, of any size, is a family business, if:

1) The majority of decision-making rights is in possession of the natural person(s) who established the firm or in the control of the natural person(s) who has/have acquired the share capital of the firm or in possession of their spouses, parents, child or children's direct heirs;

2) The majority of decision-making rights are indirect or direct; the firm.

3) At least one representative of the family or kin is formally involved in the governance of

In case of listed companies, the family businesses meet the definition of family enterprise if the person who established or acquired the share capital has 25 percent of the decision-making rights mandated by their share capital".

Handler (1989) acknowledged 4 dimensions suitable in academic works regarding the family business concerning the definition of family firms: the degree of ownership and management of family members, intergenerational transfer, interdependent subsystems, and multiple conditions. On the other hand, DeMassis et al. (2014) define the family business as a commercial organization in which the decision-making process is influenced by the succession of generations of a family, 
characterized by blood ties, marriage or adoption, and which also has the ability to influence the vision of the business and has the desire to use this ability to achieve various goals. A common feature of family businesses is their networks of social bonds - bonds both in the companies and

between the companies and outside entities (Lewandowska and Hadrys-Nowak, 2014). This may result in customer loyalty and an image of a reliable business partner. The characteristics of family businesses require that their owners/managers possess specific skills, which enable them to manage the overlapping of the family and business sphere to guarantee their existence for generations to come. That is the reason why in Europe, there has been observed the need to create special educational programs for family business owners and their successors (Lewandowska and HadrysNowak, 2014).

As for teleworking, there is no universally accepted definition of teleworking labour. The available definitions cover a wide range of homeworking, alternating telework, multi-site telework, freelance telework, mobile teleworking, and telework from relocated back offices. For this paper, we use the definition published in Commission's Status report on European Telework 1997 (EC, 1998). Accordingly, we recognize telework as the work carried out by the use of computers and telecommunications, in order to overcome restraints in place or time of work. In 2020, the International Labor Organization (ILO) stated that teleworking should be based on a voluntary arrangement between the company and the employee(s). In addition, the location of the work (at the home of the employee or somewhere else), the working hours or timetable, the communication tools to be used, the work to be accomplished, the administrative mechanisms and the appointments for reporting on the work are relevant in this accepted contract (International Labor Organization (ILO), 2020).

The recent work published by Dingel and Neiman (2020) pointed out that more than $30 \%$ of jobs can be practicably performed from home. They argue that labor performed in industries with homebased work capabilities and low face-to-face interactions (e.g. professional, scientific, and technical services) might be the lowest impacted. Also, Herrin (2013) underlined the growing importance of work facilitated by technology, proclaiming the commencement of a "Third Wave of Virtual Work".

Based on the literature reviewed, we've notice that not enough attention was devoted to family businesses and their employees, to how they were affected by the telework imposed by COVID19 and what challenges they faced. As such, in the presented setup, we developed our research questions as:

RQ1. How does the teleworking model, enforced by COVID-19 pandemic, impacted the employees' wellbeing and employees' performance in a family business?

RQ2. How did the employees perceive the teleworking model in the context of the COVID-19 pandemic?

\section{RESEARCH METHODOLOGY}

This paper employs the abductive approach developed by Peirce (1955) to detail insights regarding teleworking in time of the COVID-19 Pandemic in a family business. As a procedure of methodological reasoning, abduction functions as a relationship between deduction and induction, between logical and empirical reasoning (Mingers, 2012). This approach allows us to combine individual observations with a generic business strategy theory specific to family businesses, analogous to Hattke and Martin (2020). Also, abduction offers great promise as a potential primary mode of reasoning for qualitative research (Given, 2008). Although there has been relatively little work done using abduction, some of it characterized abduction as "reasoning to the best explanation" of an experience (Harman, 1965). 
The investigation exploits opportunities to ascertain a significant phenomenon - telework, under exceptional, unique, and extreme circumstances - COVID-19 pandemics, in a family business operating in Romania. As the case study develops, the picture created presents itself as a

composition over the tight timeframe, namely March 2020 - June 2021. Case study research method is frequently applied in family business research to date (Dyck et al., 2002; De Massis et al., 2012).

The construction materials distribution company (the Company), which is the subject of this study, is a locally important player in this market. It has been operating for 26 years now as a direct distributor in Romania of internationally recognized brands. The latest data (2021) shows that the company has 255 employees and a turnover of 42.5 million euros in 2020 , with $4.2 \%$ higher than 2019. Given its strategic position on the market of construction materials in the retail segment, its end-users, modern trade, and growing financial results, we consider the company relevant for our study.

The company is of particular interest in terms of ownership and management structure, being a family business controlled by members of a family. The founding generation was joined, in the managerial structure, by the second generation, specific aspects of family business regarding corporate governance being successfully implemented.

During our research, we conducted several individual and group interviews. Information gathered through interviews is generally claimed to be qualitative rather than quantitative. Interviews provide significant data about what sorts of relevant things are happening and how, rather than the number or magnitude of relevant factors. In this respect, we interviewed 15 employees out of the 90 working at the headquarters, from all the relevant departments such as Sales, Marketing, Financial, Legal, Human Resources, Information Technology, Public Relations and Administrative. Employees in the established sample were interviewed between February and March 2021. Women and men, aged between 25 and 59, were included in the study. The structure of interviewed persons and demographic characteristics are detailed in Appendix 1. In order to obtain a comprehensive picture of the impact of teleworking on employees' life, the sample included both management and executive functions. In this sense, the method of qualitative research of the semi-structured interview based on an interview guide was used. A list of three topics (work performance, working conditions and individual perception) and seven main predetermined research questions were established, all addressed in individual and group discussions, conducted face-to-face. The in-depth interview involved conducting a total number of 35 rounds. The subjects were very knowledgeable of the problem approached, all performing teleworking activity during the pandemic. Interviews were conducted to ensure data and data analysis's reliability and trustworthiness. In order to measure the results of the interviews, we used the methodology of operationalization of concepts, as the set of operations through which the defining properties of the notion can be identified, evaluated or even measured in the empirical universe. We also analyzed the company's information regarding financial results and internal data (both quantitative, such as financials and qualitative, such as minutes).

\section{RESULTS}

The operationalization of concepts led us to articulate some important dimensions related to remote work, addressed below.

\subsection{Work performance}

The semi-structured interviews conducted with employees revealed their major concerns: work performance and the team-coordination. About $45 \%$ of the total interview content refers to this 
topic. Employees stated that remote work is less efficient than work performed at the workplace, as they fail to complete tasks during working hours, as a result of poor separation between personal and professional life and poor communication with peers.

This self-assessed underperformance appeared to be mainly caused by a) the lack of direct and immediate contact with the information generated at the workplace, which is received late, $\mathrm{b})$ the mood of employees who do not find the motivation to work in the absence of the team or outside the classic workplace, c) the disruptive domestic factors (interruptions of workflow caused by children at home, learning online or other family members who associate the presence of the employee at home with his willingness to solve various household problems), d) the specific of the activities (some activities that can be performed exclusively at work were identified). Due to their devotion to the business, specific to family businesses, employees have identified ways to address this self-identified gap in performance by organizing the remote work schedule according to the family schedule, choosing to work very early in the morning and late in the evening. Some employees completely gave up on working remotely, on their initiative, choosing to report for work during the standard working schedule in the individual employment contract, finding that they regain the balance between work performance and attention paid to the family. Given the company's main activity's specifics, the direct sales staff experienced short-term work from home - up to one week within a month. Employees whose specific activity does not allow remote work (according to a previous analysis done by the management) perceived a lower quantitative and qualitative work performed by colleagues working remotely. In family businesses, communication and direct interaction between employees and managers and communication among employees, companies, and customers are pivotal.

\subsection{Working conditions}

The working conditions weighted $17 \%$ in the content of the interviews, based on the technique of operationalization of concepts described in the methodology section. This percentage fully reflects the importance given by the employees to this segment. A significant number of participants $(67 \%)$ considered that they do not have the necessary conditions and equipment at home to perform their professional tasks for one or more reasons related to the comfort of the workspace: they do not have space specially designated for an office at home, do not have at hand all the necessary equipment and consumables, either the furniture is inadequate or additional furniture cannot be accommodated, due to lack of space. Accomplishing work-related tasks while working remotely implies the use of specific tools and equipment. The company has constantly invested, over the last 15 years, in both software and hardware, to support the following functions: bidding, accounting, $\mathrm{HR}$ and payroll, logistics, transport, reporting. With the implementation of remote work, an additional investment plan in IT equipment (laptops, printers, scanners) was approved, generating the infrastructure necessary for employees to work from home. Given the specifics of the activity and the lack of technology at that date, employees involved in support activities (accounting, legal, environmental protection departments) considered that the main challenge in remote working was still using paper documents. As such, they used to take them home or multiplying them to be able to use them. Also, for certain periods, remote work was not an option, as some operations have a high level of confidentiality and some documents cannot be removed from the company's premises. Working conditions impact the efficiency and effectiveness of work, both for the remote worker and their colleague(s), through the need of the latter performing activities that are impossible to be carried out outside the workplace, such as verification activities in the company's archives or cash collection of customer receivables. 


\subsection{Individual perception}

We found that the attitude of employees towards remote working is different, depending on the department they belong to and their personal status. Unanimously, the interviewees expressed their desire to return to the workplace after the remote-working period ends. Most of them made statements such as "remote working ... it's an unfortunate case" (I2), "remote working is the biggest nightmare" (I3), "it's not good for our mental health" (I13), "I hope remote working ceases completely and permanently" (I4), "I would not work remotely if I were to choose" (I7) or "I do

not want to work remotely" (I6). The main reason for these approaches was the lack of socialization and interaction specific to family businesses. Employees feel united by the founder's values, taken over within the organization. Employees know and claim that teleworking is a form of personal protection against illness and a solution to preserve the human resources necessary to continue the company's activity in case of contamination of those present at work. The categories of employees who found remote working beneficial were mostly parents with children and commuters. The parents with children for whom the educational units were closed reported that working from home allows them to supervise and organize their kids' daily activities. Also, for commuters whose daily route involves more time or financial resources, teleworking meant a savings of money and time.

\section{DISCUSSION}

Throughout COVID-19 crisis, all businesses are under the pressure of crafting the acceptable balance between safeguarding a healthy and safe environment for their employees and business sustainability in terms of keeping the clients and reporting reasonable profits.

Our research aimed to shed light on how a family business operating in the construction field managed to keep its employees safe and how the employees perceived the telework style and felt about it. This single case study paper used the interview technique to assess employees' perception of telework and how telework is suitable for the foreseeable future.

Incontestable, the quality of an organization's human resources is the leading indicator of its growth and sustainability. Academic papers have revealed an extensive relationship between workplace and individual performance (Iaffaldano and Muchinsky, 1985; Judge et al., 2001; Baert et al., 2020; Kniffin et al., 2020; Vyas and Butaknieo; 2021). Similarly, our analysis reveals the employees' awareness regarding the work from home and job performance. In this particular setting of pandemics, they underlined the drawbacks experienced during telework, such as inability to focus outside the office, privation of interactions with colleagues - intensification of loneliness (Kniffin et al., 2020) or feeling of isolation (Bulinska-Stangrecka and Bagienska, 2021), unfavorable homespecific environment for work (International Organization of Employers, 2020), time for working (Tecau et al., 2020). Employees revealed challenging to maintain boundaries between work and personal life, which is in line with previous research (Ramarajan and Reid, 2013).

Though before the Pandemic in many countries, moving to telework was the norm (Hess, 2014), the Pandemic speed up this process. However, the required quarantine of workers during the COVID 19-pandemic has further complicated this matter. Similar to our findings, Salari et al. (2020) showed that working during the Pandemic generated additional stress and fatigue and positively influenced the work-family relationship and productivity. Even though in 2020, the company analyzed achieved higher profits, the particular operating field and strong competition required onsite presence. As one participant said: "... it has more to do with personalizing the relationship when you talk to the clients face to face when you look into his eyes" ( $\left.\mathrm{I}_{14}\right)$. Our results are similar to Shan and Tang's (2020) research that pointed out that companies with higher employee satisfaction are more resilient to negative shocks across the market during the COVID-19 outbreak. Consequently, our analysis highlights difficulties experienced by deficiency of discussing with 
colleagues, which can be assimilated to family members. Our respondents acknowledged the pivotal role of relational communication in personal development ( $\left.\mathrm{I}_{9}\right)$ and confirmed the results obtained by Kraus et al. (2020).

Moreover, the human resources department worked closely with all employees to make them feel protected and confident (HR, manager). Collaboration between all actors involved leads to a comfortable overcome of work from home program. The condition of mutual engagement and orientation toward the collective goal of safety is required in times of emergencies and uncertainties as COVID-19 pandemics.

On the one hand, some papers claim that teleworking is appreciated in terms of labor efficiency, comfort, time \& space management, and a mix between working from home and working in company offices (Davidescu et al., 2020) is preferred. On the other, our investigation considering the family business emphasizes employees' hope to come back in site and reconnect with colleagues and customers. The results of interviews draw attention to that remote working can contribute to employee loneliness by restraining interactions.

\section{CONCLUSIONS}

COVID-19 produced significant changes, including work and work from home became is the new normal. Currently, the work flexibility is moving toward a "business as usual" and not something to resort to in times of crisis. As a result, the pandemic was an excellent opportunity for companies and employees to reinvent themselves (Davidescu et al., 2020). In family businesses, where communication and mutual support are noteworthy, teleworking policies may be an active contingency plan to safeguard productivity, business continuity and job preservation. Shared responsibilities between employers and employees are essential in teleworking arrangements in reducing the adaptive process of homeworking.

Based on interviews, we identified some challenges related to remote work: work performance, work conditions and perceptions of employees in respect to teleworking model during 2019 COVID-19 pandemic.

As similar research, the current study has some limitations. The first is that analysis refers to a single-family business company operating on the distribution of construction materials covering only a short time span. Additionally, the presented analysis involved a limited number of interviewed individuals. To complement our findings, future research should cover a longer period and a larger number of family business companies with a comparative analysis between family business companies and corporations to lead towards original and meaningful insights from the juxtaposition of conflicting with well-established realities. Other future directions of action are regarding: (1) Digitalization, (2) Implementation of Hybrid model - Teleworking \& work from office and (3) Dynamic assessment of the employees' wellbeing.

\section{REFERENCES}

Baert, S., Lippens, L., Moens, E., Sterkens, P., \& Weytjens, J. (2020). The COVID-19 Crisis and Telework: A Research Survey on Experiences, Expectations and Hopes, IZA Discussion Papers, No. 13229 Bonn: Institute of Labor Economics (IZA)

Berg, F., Buesing, E. Gupta, V., \& Jacobson, R. (2020). Customer-care organizations: Moving from crisis management to recovery, https://www.mckinsey.com/businessfunctions/operations/our-insights/customer-care-organizations-moving-from-crisismanagement-to-recovery. 
Bhalla, V., Orglmeister, C., \& Tong, D. (2016). What makes family businesses in emerging markets so different?, https://image-src.bcg.com/Images/BCG-What-Makes-Family-BusinessesEmerging-Markets-So-Different-Sep-2016_tcm81-74598.pdf>

Bulinska-Stangrecka, H., \& Bagienska, A. (2021). The role of employee relations in shaping job satisfaction as an element promoting positive mental health at work in the era of COVID-19. International Journal of Environmental Research and Public Health 18(4), 10.3390/ijerph18041903.

Chanana, N., \& Sangeeta (2020). Employee engagement practices during COVID-19 lockdown. Journal of public affairs, e2508. https://doi.org/10.1002/pa.2508

Davidescu, A. A, Apostu, S. A., Paul, A., \& Casuneanu, I. (2020). Work Flexibility, Job Satisfaction, and Job Performance among Romanian Employees - Implications for Sustainable Human Resource Management, Sustainability, 12.

De Massis, A., Kotlar, J., Chua, J. H., \& Chrisman, J. J. (2014). Ability and Willingness as Sufficiency Conditions for Family-Oriented Particularistic Behavior: Implications for Theory and Empirical Studies. Journal of Small Business Management, 52(2), 344-364.

Deloitte (2020). COVID-19: Maintaining customer loyalty and trust during times of uncertainty, https://www2.deloitte.com/content/dam/Deloitte/ie/Documents/covid19/gx-coronaviruscustomer-loyalty.pdf

Dingel, J. I., \& Neiman, B. (2020). How many jobs can be done at home? White paper. Becker Friedman Institute, Paper_Dingel_Neiman_3.2020.pdf https://bfi.uchicago.edu/wp-content/uploads/BFI_White-

Doerr, S., \& Gambacorta, L. (2020). COVID-19 and regional employment in Europe, BIS Bulletin, 16, https://www.bis.org/publ/bisbull16.pdf

European Commission, 1998. Telework 97 - Status report on European Telework, https://cordis.europa.eu/article/id/9718-telework-97-status-report-on-european-telework

Fadinger, H., Schymik, J., \& Valipour, J. (2020). My home is my castle - the benefits of working from home during a pandemic crisis: Evidence from Germany. CEPR Discussion Paper 14871.

FBN International. (2008). Family Business International Monitor, https://www.fbn-i.org/

Fitch Ratings. (2020). Fitch Ratings Updates 2020 sector outlooks to reflect coronavirus impact, https://www.fitchratings.com/research/fund-asset-managers/fitch-ratings-updates-2020sector-outlooks-to-reflect-coronavirus-impact-27-03-2020

Given, L. M. (2008). Encyclopedia of qualitative research methods, Thousand Oaks, CA: SAGE Publications.

Handler, W. E. (1989). Methodological issues and considerations in studying family businesses. Family Business Review 2(3): 257-276.

Harman, G. (1965). Inference to the Best Explanation, The Philosophical Review 74, 88-95.

Hattke, F., \& Martin, H. (2020). Collective action during the COVID-19 Pandemic: The case of Germany's fragmented authority, Administrative Theory \& Praxis, 42(4), 614-632.

Hess, K. (2014). Death of the Office and Rise of the Telecommuter, ZDNet., http://www.zdnet.com/article/death-of-the-office-and-rise-of-the-telecommuter/.

Iaffaldano, M. T., \& Muchinsky, P. M. (1985). Job satisfaction and job performance: A metaanalysis. Psychological Bulletin, 97(2): 251-273.

IFO Institute (2020). Short-time work reaches almost all sectors in Germany, [online] Available at: < https://www.ifo.de/en/node/55086> [Accessed 30 March 2021].

International Labour Organization (ILO). (2020)c. A policy framework for tackling the economic and social impact of the COVID-19 crisis, https://www.ilo.org/wcmsp5/groups/public/@dgreports/@dcomm/documents/briefingnote/wc ms_745337.pdf 
Judge, T.A., Thoresen, C. J., Bono, J. E., \& Patton, G. K. (2001). The job satisfaction-job performance relationship: A qualitative and quantitative review. Psychological Bulletin, 127(3), 376-407.

Kniffin, K., Narayanan, J., Anseel, F., Antonakis, J., Ashford, S. P., Bakker, A. B., Bamberger, P., Bapuji, H. Bhave, D. B., Choi, V.K., Creary, Demerouti, E., Flynn, F.J., Gelfand, M.J., Greer, L., Gary S.J. et al. (2020). COVID-19 and the Workplace: Implications, Issues, and Insights for Future Research and Action, Working Paper 20-127, Harvard Business School, https://hbswk.hbs.edu/item/covid-19-and-the-workplace-implications-issues-and-insights-forfuture-research-and-action>

KPMG. (2020). Customer experience in the new reality, https://assets.kpmg/content /dam/kpmg/es/pdf/2020/11/global-customer-experience-excellence-2020.pdf

Kraus, S., Clauss, T., Breier, M., Gast, J., Zardini, A., \& Tiberius, V. (2020). The economics of COVID-19: initial empirical evidence on how family firms in five European countries cope with the corona crisis, International Journal of Entrepreneurial Behavior \& Research, vol. 26(5), 1067-1092.

Lewandowska, A., \& Hadrys-Nowak, A. (2014). Socio-economic importance of family businesses in selected countries from all over the World, https://www.researchgate.net/ publication/280531723_Socioeconomic_importance_of_family_business_in_selected_countri es_from_all_over_the_world.

Mingers, J. (2012). Abduction: The missing link between deduction and induction. A comment on Ormerod's rational inference: Deductive, inductive and probabilistic thinking, Journal of the Operational Research Society 63(6), 860-863, DOI: 10.1057/jors.2011.85

Myers, M. (2000). Qualitative Research and the Generalizability Question: Standing Firm with Proteus. The Qualitative Report, 4(3), https://nsuworks.nova.edu/cgi/ viewcontent.cgi?article $=2925 \&$ context $=$ tqr

Peirce, Charles, S. (1955). Philosophical writings of Peirce. Ed. by Justus Buchler. New York: Dover

Ramarajan, L., \& Reid, E. (2013). Shattering the myth of separate worlds: Negotiating non-work identities at work. Academy of Management Review, 38(4), 621-644.

Salari, N., Hosseinian-Far, A., Jalali, R., Vaisi-Raygani, A., Rasoulpoor, S., Mohammadi, M., Rasoulpoor, S., \& Khaledi-Paveh, B. (2020). Prevalence of stress, anxiety, depression among the general population during the COVID-19 pandemic: a systematic review and metaanalysis, Globalization and Health, 16(57), 1-16

Shan, C., \& Tang, D. Y. (2020). The value of employee satisfaction in disastrous times: evidence from COVID-19, https://ssrn.com/abstract=3560919

Silva, C. A., Montoya, R. I. A., \& Valencia, A. J. A. (2019). The attitude of managers toward telework, why is it so difficult to adopt it in organizations? Technology in Society, 59, 10.1016/j.techsoc.2019.04.009.

Tecău, A. S., Constantin, C. P., Lixăndroiu, R. C., Chițu, I. B., \& Brătucu, G., (2020). Impact of the COVID-19 Crisis on Heavy Work Investment in Romania. Amfiteatru Economic, 22(Special Issue 14), 1049-1067

Vyas, L., \& Butakhieo, N. (2021). The impact of working from home during COVID-19 on work and life domains: an exploratory study on Hong Kong, Policy Design and Practice 4(1), $59-76$ 


\section{Apendix 1}

Table 1. List of interviewed persons

\begin{tabular}{|l|c|l|l|l|}
\hline No & Acronym & Position & $\begin{array}{c}\text { Organizational } \\
\text { level }\end{array}$ & Department \\
\hline 1 & $\mathrm{I}_{1}$ & economist & management & Financial \\
\hline 2 & $\mathrm{I}_{2}$ & manager & executive & Marketing \\
\hline 3 & $\mathrm{I}_{3}$ & accountant & general & Accounting \\
\hline 4 & $\mathrm{I}_{4}$ & marketing & general & Marketing \\
\hline 5 & $\mathrm{I}_{5}$ & economist & management & Internal Control \\
\hline 6 & $\mathrm{I}_{6}$ & manager & executive & Admin \\
\hline 7 & $\mathrm{I}_{7}$ & sales & general & Sales \\
\hline 8 & $\mathrm{I}_{8}$ & manager & executive & Accounting \\
\hline 9 & $\mathrm{I}_{9}$ & IT & general & IT \\
\hline 10 & $\mathrm{I}_{10}$ & economist & general & $\begin{array}{l}\text { Environmental } \\
\text { Safety }\end{array}$ \\
\hline 11 & $\mathrm{I}_{11}$ & legal adviser & general & Legal \\
\hline 12 & $\mathrm{I}_{12}$ & PR & general & PR \\
\hline 13 & $\mathrm{I}_{13}$ & chief accountant & executive & Accounting \\
\hline 14 & $\mathrm{I}_{14}$ & sales & general & Sales \\
\hline 15 & $\mathrm{I}_{15}$ & admin officer & general & Admin \\
\hline
\end{tabular}

